\title{
Amino acids levels related to glutamine supplementation for type 2 diabetes patients.
}

\author{
Asieh Mansour ${ }^{1,2}$, Saeed Hosseini ${ }^{3}$, Mostafa Qorbani ${ }^{4,5}$, Bagher Larijani ${ }^{6}$, Mohammad Reza Mohajeri- \\ Tehrani $^{3 *}$
}

${ }^{1}$ Obesity and Eating Habits Research Center, Endocrinology and Metabolism Molecular -Cellular Sciences Institute, Tehran University of Medical Sciences, Tehran, Iran

${ }^{2}$ School of Nutritional Sciences and Dietetics, Tehran University of Medical Sciences, Tehran, Iran

${ }^{3}$ Endocrinology and Metabolism Research Center, Endocrinology and Metabolism Clinical Sciences Institute, Tehran University of Medical Sciences, Tehran, Iran

${ }^{4}$ Non-communicable Diseases Research Center, Alborz University of Medical Sciences, Karaj, Iran

${ }^{5}$ Chronic Diseases Research Center, Endocrinology and Metabolism Population Sciences Institute, Endocrinology and Metabolism Research Institute, Tehran University of Medical Sciences, Tehran, Iran

${ }^{6}$ Diabetes Research Center, Endocrinology and Metabolism Clinical Sciences Institute, Tehran University of Medical Sciences, Tehran, Iran

\begin{abstract}
Aim: Amino acids levels are changed upon glutamine administration, but the impact of glutamine administration on plasma amino acid levels in type 2 diabetes patients remains unclear.

Methods: A placebo controlled, randomized trial was performed with type 2 diabetic patients who consumed 2 supplements containing glutamine $(10 \mathrm{~g} / 3$ times a day $)$ or placebo $(1 \mathrm{~g} / 3$ times a day) every day for 6 consecutive weeks. Blood samples were obtained just before initiation of study and again after the patients had received the study supplements.

Results: Dietary supplementation with glutamine didn't affect concentrations of plasma amino acid apart from for threonine. Plasma threonine concentration in intervention group was low at week 6

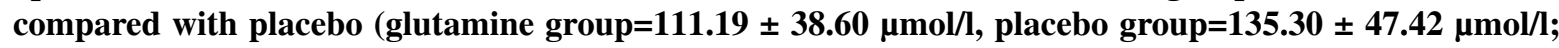
$\mathbf{P}=\mathbf{0 . 0 2}$ ).

Conclusion: In type 2 diabetes patients, oral glutamine supplementation resulted in a decreased level of threonine.
\end{abstract}

Keywords: Amino acids, Glutamine, Threonine, Type 2 diabetes.

Accepted on June 08, 2018

\section{Introduction}

Glutamine as "conditionally essential" amino acid is the most abundant element in human blood and serves not only the role as regulator of acid-base homeostasis and in gluconeogenes, but also plays roles as a "nitrogen shuttle" between various organs, involved in as a an important oxidative fuel for rapidly proliferating cells including enterocytes, reticulocytes and immune cells. Also, glutamine has a signaling role in many processes including cell proliferation [1-3]. Dietary intake of glutamine has previously been demonstrated to be a strong stimulant of GLP-1 release leading to an effect associated with increased insulin circulation [4,5]. More recently, evidence available to determine whether oral glutamine is necessary or beneficial when consumed in patients with type 2 diabetes
$[5,6]$. Results of previous studies have indicated the absence of adverse effect of glutamine administration in adult human when consumed in 0.57-0.75 g. $\mathrm{kg}^{-1}$ per day [7].

To date, it is unknown whether dietary glutamine can exert influence on aminoacidemia in diabetes patients. So that in a number of published studies either a short duration of glutamine administration was investigated in non-diabetic population or were done in animal models [8-11]. Also, little is known about its effects on plasma concentrations of amino acid in humans and animals. These concerns limit our confidence for oral administration of glutamine to type 2 diabetes and underscore the need for longer study. Here, in this article, we aimed to examine the influences of a glutamineenriched diet on aminoacidemia that may raise the risk of 
health problem through the alteration in amino acids levels in blood.

\section{Methods}

A total of 66 adults with type 2 diabetes participated in this study, which was approved by Tehran University of Medical Sciences Ethics Committee registration number 197, and registered at IRCT, registration number IRCT201205279373N1. All tests were performed in the morning after an overnight fast. Blood samples were put in to EDTA tubes and centrifuged for $15 \mathrm{~min}$ at $2500 \mathrm{~g}$. The plasma concentration of free amino acids were determined by HPLC. The inclusion criteria into the study were having a BMI (in $\left.\mathrm{kg} / \mathrm{m}^{2}\right)<35$, blood pressure $<160 / 90 \mathrm{mmHg}$. Exclusion criteria for both groups were hepatic or renal disorder, malignancy, autoimmune diseases and history of drug abuse. In addition, patients who were using a restrictive diet or weight change $>5$ $\mathrm{kg}$ before the study were excluded. Moreover, patients with a history of prior corticosteroids use, hormones therapy or using antibiotic drugs, taking any medication known for weight loss, and treatment with anti-inflammatory medication were excluded from the study. Following baseline examination, all eligible participants were randomly assigned to one of two groups: $10 \mathrm{~g} / 3$ times a day of glutamine; or $1 \mathrm{~g} / 3$ times a day placebo in a double blind manner. All tests were repeated following a 6-week therapy. Pre to post differences were analyzed using a general linear model ANCOVA and baseline differences between two groups were analyzed using independent samples t-test. Data were analyzed using the Statistical Package for the Social Sciences version 18 (SPSS Inc., Chicago, IL). Significance level was taken as $\mathrm{P}<0.05$.

\section{Results}

53 males and females, 27 in the glutamine group and 26 in the placebo group who aged $51.5 \pm 6.89 \mathrm{y}$; mean $\pm \mathrm{SD}$, and had diabetes (glutamine group=73.64 \pm 14.72 months, placebo group $=75.16 \pm 54.62$ months; mean $\pm \mathrm{SD}, \mathrm{P}=0.71$ ), completed the trial and were included in the statistical analyses. Holecek published a review oPlasma amino acid profiles are shown in Table 1. No differences were observed between groups in terms of plasma concentration of free amino acid before the trial. After 6 weeks of supplementation with glutamine, there were no significant differences in amino acid levels, excepting threonine levels at week 6 (glutamine group $=111.19 \pm 38.60$ $\mu \mathrm{mol} / \mathrm{l}$, placebo group=135.30 $\pm 47.42 \mu \mathrm{mol} / \mathrm{l} ; \mathrm{P}=0.02$ ), which showed a significant decrease in glutamine group in comparison with placebo.

Table 1. Plasma amino acid concentration in baseline and after 6 weeks glutamine supplementation.

\begin{tabular}{llll}
\hline Amino acids & Glutamine $(n=27)(\mu \mathrm{mol} / \mathrm{l})$ & Placebo $(\mathrm{n}=26)(\boldsymbol{\mu m o l} / \mathrm{l})$ & $\begin{array}{l}\mathbf{P} \\
\text { value }\end{array}$ \\
\hline Aspartate & & & \\
\hline Baseline & $8.00 \pm 3.16$ & $8.91 \pm 3.94$ & 0.36
\end{tabular}

\begin{tabular}{|c|c|c|c|}
\hline Week 6 & $6.54 \pm 3.48$ & $6.04 \pm 2.52$ & 0.61 \\
\hline \multicolumn{4}{|l|}{$\begin{array}{l}\text { Glutamic } \\
\text { acid }\end{array}$} \\
\hline Baseline & $99.38 \pm 44.13$ & $95.46 \pm 35.20$ & 0.72 \\
\hline Week 6 & $105.71 \pm 52.24$ & $116.94 \pm 60.46$ & 0.36 \\
\hline \multicolumn{4}{|c|}{ Asparagine } \\
\hline Baseline & $47.45 \pm 15.12$ & $49.89 \pm 16.23$ & 0.57 \\
\hline Week 6 & $40.47 \pm 11.60$ & $41.85 \pm 12.04$ & 0.86 \\
\hline \multicolumn{4}{|l|}{ Serine } \\
\hline Baseline & $123.35 \pm 48.10$ & $120.96 \pm 33.95$ & 0.83 \\
\hline Week 6 & $107.77 \pm 38.67$ & $110.86 \pm 37.84$ & 0.44 \\
\hline \multicolumn{4}{|l|}{ Histidine } \\
\hline Baseline & $108.98 \pm 35.84$ & $128.27 \pm 60.09$ & 0.16 \\
\hline Week 6 & $75.10 \pm 19.84$ & $75.37 \pm 21.56$ & 0.61 \\
\hline \multicolumn{4}{|c|}{ Glutamine } \\
\hline Baseline & $493.92 \pm 154.00$ & $536.76 \pm 147.20$ & 0.31 \\
\hline Week 6 & $498.52 \pm 182.75$ & $486.44 \pm 151.66$ & 0.49 \\
\hline \multicolumn{4}{|l|}{ Arginine } \\
\hline Baseline & $37.31 \pm 14.38$ & $43.72 \pm 22.88$ & 0.23 \\
\hline Week 6 & $36.12 \pm 17.92$ & $36.28 \pm 19.32$ & 0.62 \\
\hline \multicolumn{4}{|l|}{ Citrulline } \\
\hline Baseline & $21.82 \pm 9.01$ & $24.01 \pm 12.26$ & 0.46 \\
\hline Week 6 & $24.79 \pm 13.77$ & $26.53 \pm 11.04$ & 0.71 \\
\hline \multicolumn{4}{|l|}{ Glycine } \\
\hline Baseline & $269.64 \pm 180.42$ & $317.72 \pm 128.68$ & 0.27 \\
\hline Week 6 & $171.00 \pm 80.14$ & $215.52 \pm 97.96$ & 0.17 \\
\hline \multicolumn{4}{|c|}{ Threonine } \\
\hline Baseline & $143.64 \pm 52.09$ & $138.82 \pm 39.92$ & 0.71 \\
\hline Week 6 & $111.19 \pm 38.60$ & $135.30 \pm 47.42$ & $0.02^{*}$ \\
\hline \multicolumn{4}{|c|}{ isoleucine } \\
\hline Baseline & $75.78 \pm 21.21$ & $76.42 \pm 27.97$ & 0.92 \\
\hline Week 6 & $84.66 \pm 27.66$ & $84.22 \pm 27.02$ & 0.94 \\
\hline \multicolumn{4}{|l|}{ Leucine } \\
\hline Baseline & $138.04 \pm 35.19$ & $141.61 \pm 44.80$ & 0.75 \\
\hline Week 6 & $153.23 \pm 44.84$ & $155.34 \pm 45.41$ & 0.88 \\
\hline \multicolumn{4}{|l|}{ Alanine } \\
\hline Baseline & $511.30 \pm 163.94$ & $562.88 \pm 172.46$ & 0.27 \\
\hline Week 6 & $422.99 \pm 99.89$ & $498.59 \pm 142.95$ & 0.19 \\
\hline \multicolumn{4}{|l|}{ Tyrosine } \\
\hline Baseline & $65.76 \pm 27.73$ & $68.33 \pm 22.42$ & 0.71 \\
\hline
\end{tabular}




\begin{tabular}{|c|c|c|c|}
\hline Week 6 & $69.77 \pm 20.67$ & $75.10 \pm 20.94$ & 0.39 \\
\hline \multicolumn{4}{|c|}{ Tryptophan } \\
\hline Baseline & $49.97 \pm 14.79$ & $56.69 \pm 18.14$ & 0.14 \\
\hline Week 6 & $64.61 \pm 19.99$ & $68.10 \pm 17.72$ & 0.61 \\
\hline \multicolumn{4}{|c|}{ Methionine } \\
\hline Baseline & $26.34 \pm 7.76$ & $27.10 \pm 8.21$ & 0.73 \\
\hline Week 6 & $27.57 \pm 7.09$ & $30.14 \pm 7.02$ & 0.2 \\
\hline \multicolumn{4}{|l|}{ Valine } \\
\hline Baseline & $241.23 \pm 60.78$ & $250.49 \pm 77.28$ & 0.63 \\
\hline Week 6 & $270.44 \pm 83.25$ & $277.27 \pm 76.11$ & 0.79 \\
\hline \multicolumn{4}{|c|}{$\begin{array}{l}\text { Phenylalanin } \\
\text { e }\end{array}$} \\
\hline Baseline & $56.28 \pm 12.33$ & $61.20 \pm 13.91$ & 0.18 \\
\hline Week 6 & $63.74 \pm 14.93$ & $66.03 \pm 16.42$ & 0.63 \\
\hline \multicolumn{4}{|l|}{ Ornithine } \\
\hline Baseline & $99.66 \pm 56.00$ & $87.87 \pm 47.86$ & 0.41 \\
\hline Week 6 & $89.87 \pm 41.65$ & $111.96 \pm 57.69$ & 0.12 \\
\hline \multicolumn{4}{|l|}{ Lysine } \\
\hline Baseline & $174.67 \pm 65.87$ & $151.66 \pm 63.63$ & 0.2 \\
\hline Week 6 & $155.73 \pm 65.49$ & $178.66 \pm 56.02$ & 0.23 \\
\hline \multicolumn{4}{|c|}{$\begin{array}{l}\text { Values are mean } \pm \text { SEM; ANCOVA } P \text { value for comparison between glutamine } \\
\text { and placebo groups at the end of study. Independent samples t-test } P \text { value fo } \\
\text { comparison between glutamine and placebo groups at the baseline. "Significan } \\
\text { was taken as } P<0.05 \text {. }\end{array}$} \\
\hline
\end{tabular}

\section{Discussion}

These results indicate that supplementary glutamine decreased serum concentrations of the threonine in type 2 diabetes patients. Threonine is a major component of intestinal mucin protein and there is evidence indicating that threonine plays an important role in many physiological and biochemical processes including modulating immune function, inhibition of apoptosis, stimulation of lymphocyte proliferation, and glycine synthesis $[12,13]$. Since threonine is involved in a number of important metabolic functions, therefore, a decrease in protein synthesis and severe metabolic alterations is partly caused by its reduction [14]. The mechanisms for glutamine-induced decrease in threonine concentration in plasma remain to be elucidated. In their rodent models, Moundras et al. showed that this decrease may be as a consequence of upregulation of serine (threonine) dehydratase by glutamine [15].

It has been established that glutamine supplementation raises and lowers the plasma levels of several amino acid levels (is not homogeneous) depends on various factors which are related to the choice of the form, doses and method (enteral or parenteral) on which it may be administrated and likely to depend on many other different factors, including the nature of disease and its severity [16]. Our results are in agreement with Holecek who observed a significant reduction in threonine in plasma following 3 months of an increased consumption of glutamine in male Wistar rats [1]. Similarly in male SpragueDawley rats, Jeevanandam et al. found a significant reduction in plasma levels of threonine following $4 \mathrm{~d}$ of supplementation with glutamine in intact rats [10]. They also observed a decrease in the plasma levels of this amino acid in the traumatized rats group; however, it did not reach statistical significance. The absence of any changes in plasma levels of several amino acids except threonine after long-term glutamine administration with each main meal seems be in contrast with studies that assessed the plasma amino acid response to the ingestion of diet enriched with glutamine in rodents models and also in human $[1,10,17,18]$.

Holecek published a review on the side effects of glutamine supplementation, in which he concluded that despite its noticeable alterations in aminoacidemia, the short-term use of glutamine can be safely consumed in large amount [16]. However, studies focused on the impact of glutamine on aminoacidemia among human are subject to limitations. Dechelotte et al. tested plasma levels of amino acid in healthy volunteers inserted nasojejunal tube (enterally administrated glutamine) over 1 or $2.5 \mathrm{~h}$ [9]. Svanberg et al. tested such effect in healthy volunteers by glutamine provision (intravenously) over $2.5 \mathrm{~h}$ in 5 males, and Rutten et al. investigated the amino acid levels from 8 chronic obstructive pulmonary disease patients $80 \mathrm{~min}$ after glutamine drink and then compared the results with those of 8 healthy individuals [19,20]. Moreover, a large proportion of these studies analyzing aminoacidemia after glutamine intake used only one arm with no comparison between different subgroups $[9,17,18]$. As well, another limitation to consider is the duration of studies which were short. Such limitation was resolved in this study by including an arm (placebo group) and increasing the duration of study time.

Evidence has been reported that of the oxidation rate of glutamate and the activity of glutamine synthesis were reduced in the diabetic retina. Elevated glutamate is thought to play a significant role in the pathogenesis of diabetic retinal neurodegeneration by overstimulation of its receptors [21]. In our study, we found no evidence of a significant increase in plasma glutamate levels due to glutamine supplementation.

\section{Conclusion}

It is therefore suggested that the enhancement of glutamine intake contributes to the depletion of plasma threonine. Further research should be carried out for a better understanding of the physiological role of these finding.

\section{References}

1. Holecek M. Adverse effects of chronic intake of glutamine-supplemented diet on amino acid concentrations and protein metabolism in rat: Effect of short-term starvation. E Spen Eur E J Clin Nutr Metab 2011; 6: 190-196. 
2. Rao R, Samak G. Role of glutamine in protection of intestinal epithelial tight junctions. $\mathrm{J}$ Epithel Biol Pharmacol 2012; 5: 47.

3. Zellner M, Gerner C, Eliasen MM. Glutamine starvation of monocytes inhibits the ubiquitin-proteasome proteolytic pathway. Biochim et Biophys Acta 2003; 1638: 138-148.

4. Reimann F, Williams L, da Silva Xavier G, Rutter GA, Gribble FM. Glutamine potently stimulates glucagon-like peptide-1 secretion from GLU Tag cells. Diabetologia 2004; 47: 1592-1601.

5. Greenfield JR, Farooqi IS, Keogh JM. Oral glutamine increases circulating glucagon-like peptide 1, glucagon, and insulin concentrations in lean, obese, and type 2 diabetic subjects. Am J Clin Nutr 2009; 89: 106-113.

6. Samocha-Bonet D, Wong O, Synnott E-L. Glutamine reduces postprandial glycemia and augments the glucagon-like peptide-1 response in type 2 diabetes patients. J Nutr 2011; 141: 1233-1238.

7. Watford M. Glutamine metabolism and function in relation to proline synthesis and the safety of glutamine and proline supplementation. J Nutr 2008; 138: 2003-2007.

8. Ockenga J, Borchert K, Stüber E, Lochs H, Manns MP, Bischoff SC. Glutamine-enriched total parenteral nutrition in patients with inflammatory bowel disease. Eur J Clin Nutr 2005; 59: 1302-1309.

9. Dechelotte P, Darmaun D, Rongier M, Hecketsweiler B, Rigal O, Desjeux J-F. Absorption and metabolic effects of enterally administered glutamine in humans. Am J Physiol Gastrointest Liver Physiol 1991; 260: 677-682.

10. Jeevanandam M, Holaday NJ, Petersen SR. Altered brain and muscle amino-acid levels due toremote injury during glutamine supplementation. Clin Nutr 1995; 14: 365-372.

11. Holecek M, Skopec F, Skalská H, Šprongl L. Effect of alanyl-glutamine on leucine and protein metabolism in endotoxemic rats. J Parenter Enteral Nutr 2000; 24: 215-222.

12. Li P, Yin Y-L, Li D, Kim SW, Wu G. Amino acids and immune function.Br J Nutr 2007; 98: 237-252.

13. Wu G. Amino acids: metabolism, functions, and nutrition. Amino Acids 2009; 37: 1-17.

14. Di Pasquale MG. Amino acids and proteins for the athlete: The anabolic edge Boca Raton, FL. CRC Press 2007.
15. Moundras C, Rémésy C, Bercovici D, Demigné C. Effect of dietary supplementation with glutamic acid or glutamine on the splanchnic and muscle metabolism of glucogenic amino acids in the rat. J Nutr Biochem 1993; 4: 222-228.

16. Holecek M. Side effects of long-term glutamine supplementation. J Parenter Enteral Nutr 2012; 0148607112460682.

17. Melis GC, Boelens PG, van der Sijp JRM. The feeding route (enteral or parenteral) affects the plasma response of the dipetide Ala-Gln and the amino acids glutamine, citrulline and arginine, with the administration of Ala-Gln in preoperative patients. Br J Nutr 2005; 94: 19-26.

18. Valencia E, Marin A, Hardy G. Impact of oral Lglutamine on glutathione, glutamine, and glutamate blood levels in volunteers. Nutrition 2002; 18: 367-370.

19. Svanberg E, Möller-Loswick, A-C, Matthews DE, Körner $\mathrm{U}$, Lundholm K. The effect of glutamine on protein balance and amino acid flux across arm and leg tissues in healthy volunteers. Clin Physiol 2001; 21: 478-489.

20. Rutten EPA, Engelen MPKJ, Wouters EFM, Schols AMWJ, Deutz NEP. Metabolic effects of glutamine and glutamate ingestion in healthy subjects and in persons with chronic obstructive pulmonary disease. Am J Clin Nutr 2006; 83: 115-123.

21. Tombran-Tink J, Barnstable CJ, Gardner TW. Visual dysfunction in diabetes: The science of patient impairment and health care. Springer Science and Business Media 2011.

\section{*Correspondence to}

Mohammad Reza Mohajeri-Tehrani

Endocrinology and Metabolism Research Center

Endocrinology and Metabolism Clinical Sciences Institute

Tehran University of Medical Sciences

Tehran

Iran 